\title{
A Missed and Delayed Detected Fish Bone Impaction in Subglottis
}

\author{
Chung Man Sung, Hyung Chae Yang, Sung Min Jin, and Chul Ho Jang \\ Department of Otolaryngology-Head and Neck Surgery, Chonnam National University Medical School and \\ Chonnam National University Hospital, Gwangju, Korea
}

\author{
지연 발견된 성문하 기도 이물 \\ 성충만 · 양형채 · 진성민 · 장철호 \\ 전남대학교 의과대학 전남대학교병원 이비인후과학교실
}

\author{
Received April 5, 2017 \\ Revised June 12, 2017 \\ Accepted June 20, 2017 \\ Address for correspondence \\ Chul Ho Jang, MD, PhD \\ Department of Otolaryngology- \\ Head and Neck Surgery, \\ Chonnam National University \\ Medical School and \\ Chonnam National University \\ Hospital, 42 Jebong-ro, Dong-gu, \\ Gwangju 61469, Korea \\ Tel $+82-62-220-6776$ \\ Fax +82-62-228-7743 \\ E-mail chulsavio@hanmail.net
}

Laryngeal foreign body can be a life-threatening emergency. Respiratory distress, aphonia, and cyanosis may occur in quick succession. However, in case of a non-obstructive laryngeal foreign body, symptoms can be indolent, but the hazardous foreign body can nevertheless put the patient in danger. To prevent life-threatening consequences, early detection based on symptoms is imperative. This case, which presented with usual symptoms of anterior neck pain and throat discomfort without respiratory symptoms and an unusual site of laryngeal foreign body, finally turned out to be an impacted fish bone in the subglottis.

Korean J Otorhinolaryngol-Head Neck Surg 2019;62(1):57-9

Key Words Endoscopic assessment · Foreign bodies $\cdot$ Laryngoscope $\cdot$ Larynx $\cdot$ Trachea.

\section{Introduction}

Fish bone is one of the most commonly swallowed foreign bodies. However, a fish bone is a relative uncommon material for impaction in the laryngotracheal airway in a healthy adult due to the protective mechanism of the airways comprising the epiglottis and arytenoids and the cough reflex. ${ }^{1)}$ The symptoms of pharyngo-esophageal foreign bodies include dysphagia, foreign body sensation, and neck pain. In contrast, laryngotracheal foreign bodies present with airway related symptoms such as cough, wheeze, stridor, aphonia, or respiratory distress. These symptoms, although helpful in diagnosing a foreign body, are alarming to the doctor.

This is an Open Access article distributed under the terms of the Creative Common Attribution Non-Commercial License (https://creativecommons.org/licenses/by-nc/4.0) which permits unrestricted non-commercial use, distribution, and reproduction in any medium, provided the original work is properly cited.
Laryngeal foreign body impaction can be life threatening. However, with some non-obstructive laryngeal foreign bodies, symptoms can be indolent. Nevertheless, such indolent foreign bodies finally cause erosion or obstruction, which can lead to pneumonia, atelectasis, or abscess. ${ }^{2}$ Thus, suspicion of a foreign body should be followed by prompt removal of the same in the initial evaluation itself for preventing complications. However, if the patient presents with only non-respiratory symptoms, a laryngeal foreign body can be overlooked and misdiagnosed, which may finally result in a catastrophic event.

In this case report, we present an unusual case of laryngeal foreign body. A patient with anterior neck pain and throat discomfort without respiratory symptoms was misdiagnosed to have a pharyngeal foreign body. However, it was eventually diagnosed as a subglottic fish bone impaction. 


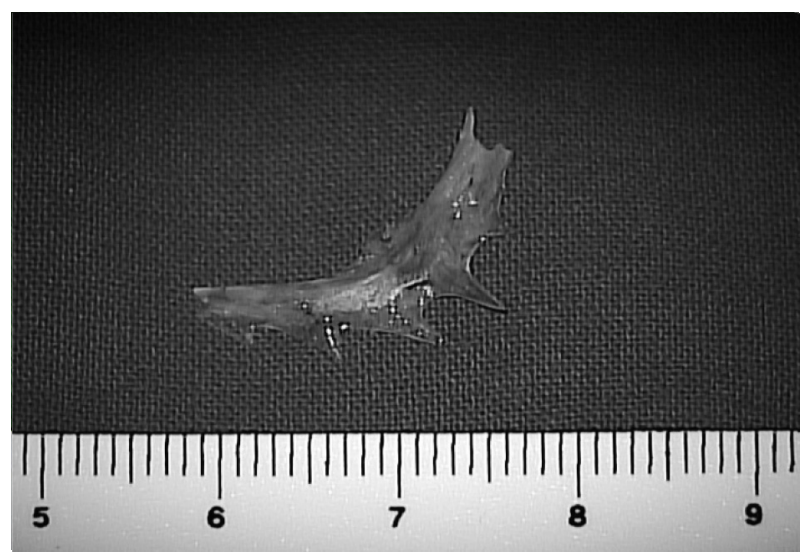

Fig. 1. A subglottic fish bone. A foreign object was observed through the rima glottis.

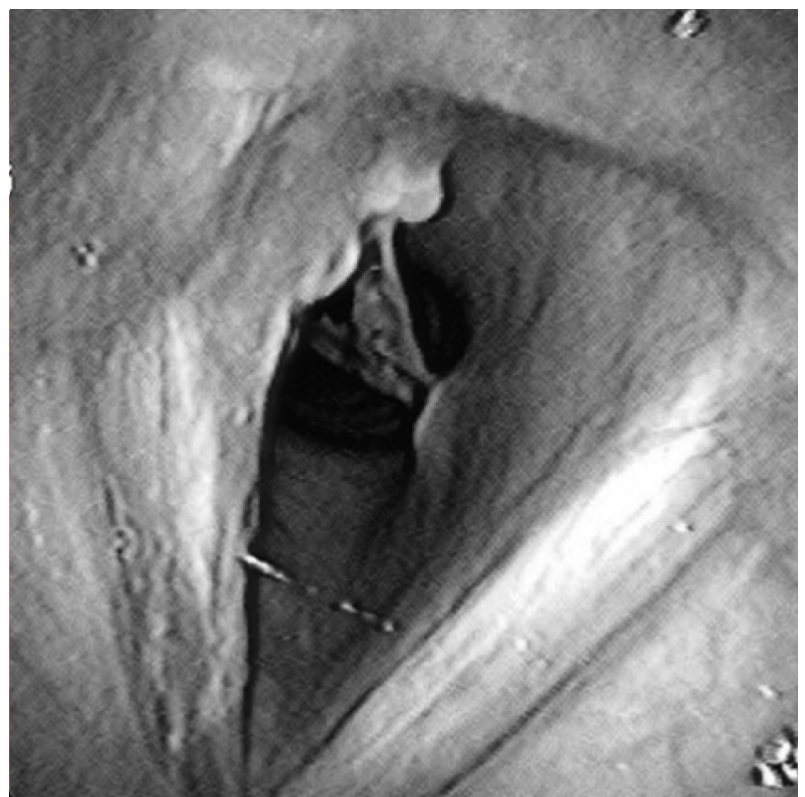

Fig. 2. A 2-cm sized fish bone was disengaged from the subglottic mucosa.

\section{Case}

A healthy 55-year-old woman with no underlying disease presented with throat pain and foreign body sensation in the neck without any difficulty in breathing. She had been in pain for 3 days following the consumption of fish. Upon evaluation using a flexible laryngoscope, no foreign body was detected. After a week, she revisited our clinic because of throat pain, but had no difficulty in breathing. Another flexible endoscopic examination was performed. Upon examination, a fish bone was observed within the rima glottis (Fig. 1, Video 1). In addition, we performed the cervical plain film lateral view and the neck computed tomography (CT) to distinguish the exact location, structure, and other lesions. We could not

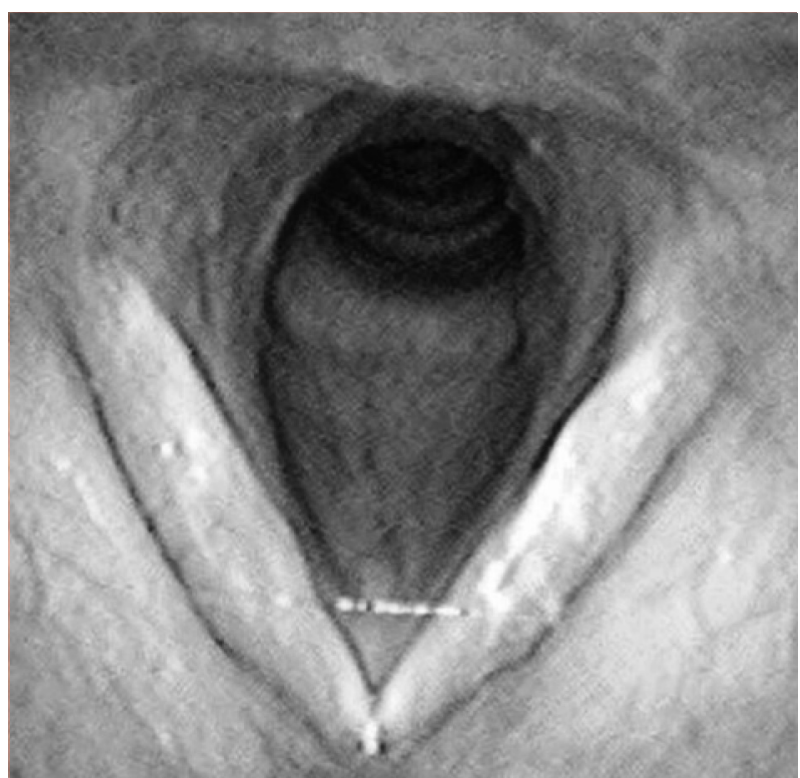

Fig. 3. One week after removal, the true vocal cord and the subglottic tissue.

identify any abnormal findings in the cervical plain film, but we could identify the foreign body located in the suglottis in the neck CT. Emergency surgery was performed under general anesthesia. Oxygen saturation was maintained through mask bagging because of the inability to perform intubation. When oxygen saturation was sufficiently elevated, while mask bagging was stopped, the fish bone was removed by direct laryngoscopy (Fig. 2). One week after removal, the subglottic tissue had completely healed (Fig. 3).

\section{Discussion}

Foreign body aspiration usually occurs in children less than 3 years of age with a peak between the first and second birthdays. ${ }^{3,4)}$ They tend to put the foreign object into their mouth and continue to talk, laugh, and run while chewing it. In adults, the most commonly ingested foreign body is a fish bone and the locations for fish bones discovered are known to occur mainly in the palatine tonsils, base of the tongue, valleculae, and the pyriform sinus. ${ }^{5)}$ A foreign body in the airways is uncommon due to airway protection mechanisms. ${ }^{1)}$ However, once it does happen, it can be a life-threatening emergency.

Respiratory symptoms are helpful in the early diagnosis of laryngeal foreign bodies. Foreign bodies in the larynx usually cause dysphagia, dyspnea, cough, wheeze, stridor, or acute respiratory obstruction. However, some foreign bodies that do not cause obstruction can lead to indolent symptoms. ${ }^{6-8)}$ If the correct diagnosis is not made at the initial evaluation, re- 
flexes become relaxed, leading to less pronounced symptoms; this condition may be misdiagnosed as some other condition, such as asthma. ${ }^{6,7)}$ However, the complications of such misdiagnosed retained foreign bodies would manifest as erosion or obstruction leading to pneumonia, atelectasis, or abscess. ${ }^{2)}$

If fish bone lodge in the oropharynx, it can be confirmed relatively easily using pharyngeal mirrors or flexible nasopharyngoscopy. When impaction occurs in less common areas, such as at the cricopharyngeus or cervical oesophagus, radiological examinations may be helpful in diagnosis. ${ }^{9)}$ Cervical plain film is a relatively simple method used for evaluation of impacted foreign body, but it has poor sensitivity when the foreign body is fish bone or food. CT is a useful diagnostic method with high sensitivity and specificity. Therefore, it can be performed when the location of the foreign body is unknown or there is accompanying complication. Endoscopic examination, such as esophagoscopy and bronchoscopy, is a good method to perform treatment at the same time as diagnosis. However, if the impaction is prolonged, it may be difficult to identify foreign body due to inflammation of the surrounding tissue. ${ }^{5,10)}$

Insufflation catheter, bronchoscope, telescope-guided foreign body grasper, or direct laryngoscopy can be used for foreign body removal according to the type and site of the foreign body. Among foreign bodies, sharp objects such as fish bones are extremely challenging to remove. ${ }^{11,12)}$ They can damage the impacted mucosa and can be bent or broken. Hence, the operator, after placing an endoscope into the airway, disengages the sharp end of the foreign object from the mucosa, moves it distally, and then removes it using foreign body forceps. ${ }^{11)}$

In this case, the patient presented with throat pain and foreign body sensation in the neck without respiratory symptoms. Foreign body sensation and throat pain are unusual symptoms for a laryngeal foreign body. These are the symptoms of a pharyngeal foreign body lodged in the neck. At the initial examination, we suspected a pharyngeal foreign body rather than laryngeal foreign body as we had missed the subglottic fish bone. However, during the second flexible laryngoscopy, which was performed within a week, we detected the foreign body in the rima glottis.

We rechecked the pictures obtained with the initial examination, which revealed that the vocal cords were almost adducted during inspiration. Considering that the recurrent laryngeal nerve provides both subglottic mucosa sensory innervation and the vocal cord adductor motor innervation, ${ }^{13)}$ noxious stimulation produced by the subglottic fish bone may cause vocal cord closure at the early phase of fish bone impaction. Thus, the examiner missed the subglottic fish bone.

In this case, the patient presented with unusual symptoms of a laryngeal foreign body. Considering the possibility of a life-threatening event because of foreign body impaction, routine examination of the subglottic area via flexible laryngoscopy or bronchoscopy is recommended even when patients do not have respiratory symptoms and complain only of ambiguous symptoms, especially in patients with a possible history of laryngeal foreign body.

Supplementary Video 1. A flexible laryngoscopic examination of a subglottic fish bone. A foreign object was observed in subglottis.

\section{Acknowledgments}

This research was supported by the Bio \& Medical Technology Development Program of National Research Foundation of Korea (NRF) funded by the Korean government MSIP (NRF-2017M3A9E8023021).

\section{REFERENCES}

1) Figueiredo RR, Machado WS. Aspiração de corpo estranho através de traqueotomia: descrição de um caso. Rev Bras Otorrinolaringol 2005;71(2):234-6.

2) Kansara AH, Shah HV, Patel MA, Manjunatharao SV. Unusual case of laryngeal foreign body. Indian J Otolaryngol Head Neck Surg 2007;59(1):63-5.

3) Banerjee A, Rao KS, Khanna SK, Narayanan PS, Gupta BK, Sekar JC, et al. Laryngo-tracheo-bronchial foreign bodies in children. J Laryngol Otol 1988;102(11):1029-32.

4) Kadmon G, Stern Y, Bron-Harlev E, Nahum E, Battat E, Schonfeld T. Computerized scoring system for the diagnosis of foreign body aspiration in children. Ann Otol Rhinol Laryngol 2008;117(11): 839-43.

5) Kim JP, Kwon OJ, Shim HS, Kim RB, Kim JH, Woo SH. Analysis of clinical feature and management of fish bone ingestion of upper gastrointestinal tract. Clin Exp Otorhinolaryngol 2015;8(3):261-7.

6) Rafanan AL, Mehta AC. Adult airway foreign body removal. What's new? Clin Chest Med 2001;22(2):319-30.

7) Akgedik R, Aytekin I, Kurt AB, Eren Dağlı C. Recurrent pneumonia due to olive aspiration in a healthy adult: a case report. Clin Respir J 2016;10(6):809-10.

8) Sun YL, Bao Z, Wang XF, Wang LH, Zhou JY. The tracheobronchial foreign body in welder without the history of allotriophagy and foreign body aspiration. Clin Respir J 2016;10(5):666-70.

9) Shetty D, Gay DA. The lateral neck radiograph for an impacted fish bone in the aero-digestive tract: going back to basics. J Biomed Sci Eng 2012;5:826-8.

10) Ngoo KS, Ramzisham AR, Joanna OS, Zamrin DM. Foreign body aspiration in an adult: the great mimic. Med J Malaysia 2008;63(1): 61-2.

11) Holinger LD. Management of sharp and penetrating foreign bodies of the upper aerodigestive tract. Ann Otol Rhinol Laryngol 1990;99 (9 Pt 1):684-8.

12) Inglis AF Jr, Wagner DV. Lower complication rates associated with bronchial foreign bodies over the last 20 years. Ann Otol Rhinol Laryngol 1992;101(1):61-6.

13) Sasaki CT. Anatomy and development and physiology of the larynx [cited 2017 Mar 5]. Available from: URL: http://www.nature.com/gimo/ contents/pt1/full/gimo $7 . h t m l$. 